\title{
A neonatal case of pial arteriovenous fistulas and the review of literature
}

\author{
(D)Mehmet Şah İpek ${ }^{1}$, @DAdil Yılmaz ${ }^{2}$ \\ ${ }^{1}$ Memorial Dicle Hospital, Division of Neonatology, Department of Pediatrics, Diyarbakır, Turkey \\ ${ }^{2}$ Memorial Dicle Hospital, Department of Neurosurgery, Diyarbakır, Turkey
}

Cite this article as: İpek MŞ, Yllmaz A. A neonatal case of pial arteriovenous fistulas and the review of literature. J Health Sci Med 2021; 4(4): 520-523.

\begin{abstract}
Pial arteriovenous fistulas (PAVFs) are extremely rare vascular malformations of the brain, and associated with greater morbidity and mortality in neonates and infants. We reported a neonatal case of giant multi-hole PAVFs presented with heart failure and local brain atrophy. The challenges associated with the complexity, outcome and therapeutic options of neonatal PAVFs were discussed. In addition, a review of the published literature on cases of PAVFs diagnosed at neonatal age, over the last two decades, was performed. Comprehensive prognostic evaluation and an optimal treatment strategy offered by a multidisciplinary team at specialized centers should be assured for each case affected.
\end{abstract}

Keywords: Pial arteriovenous fistula, cerebral arteriovenous malformation, treatment, outcome, neonate

\section{INTRODUCTION}

Pial arteriovenous fistulas (PAVFs) are extremely rare vascular lesions of the brain. They are comprised of single or multiple arterial feeders draining directly into the venous channel without intervening tangle of blood vessels (1-3). It has been estimated that they make up approximately $1.6 \%$ of all intracranial vascular malformations in the general population, and up to $7.3 \%$ in the pediatric population (1-4). The morbidity and mortality associated with this anomaly seem higher in the neonatal period due to more complicated vasculature and age-related features (2-7). Herein, a neonatal case of giant multi-hole PAVFs presented with heart failure and local brain atrophy is discussed. The informed consent was obtained from the parents to publish this case.

\section{CASE REPORT}

A 10-day-old male infant was referred to the neonatal intensive care unit for cardiomegaly. He was the first child of a non-consanguineous marriage, born vaginally at 38 weeks of gestation. Despite irregular antenatal visits, the antenatal course was uncomplicated, and there was no history of skin lesions or vascular malformation in the family. On the fifth day after birth, he was admitted to a hospital where he received intravenous fluids because of poor feeding and dehydration. There the results of baseline laboratory tests were unremarkable, but chest radiograph showed increased the heart size, and therefore he was transitioned for further evaluation. On admission, he had decreased responsiveness with poor feeding, respiratory rate of 68 breaths per minute without retractions, heart rate of 184 beats per minute and caput succedaneum. On auscultation, a continuous murmur had been heard over his anterior fontanelle. The rest general examination, as well as routine laboratory analyses were unremarkable. During hospitalization, left-sided focal seizures were detected, and taken under control with anticonvulsant. Echocardiography revealed that the heart was structurally normal but grossly enlarged with moderately affected function. Transfontanelle ultrasound showed a significantly increased blood flow within the right hemisphere, indicating a brain magnetic resonance angiography and venography imagination. Brain T2-weighted magnetic resonance image (MRI) showed a giant PAVF in the right hemisphere with parenchymal destruction (Figure). The patient was consulted to the experts from pediatric neurosurgery and pediatric neurology. The parents were thoroughly informed about the complications of the interventions and poor prognosis, and then offered them to refer the patient to a specialized center which unfortunately only very few are available in the country. Because of socioeconomic reasons and apparently poor 
outcome, they refused further interventions at that moment. After two weeks of the discharge with medical treatment for cardiac failure and seizures, the patient suddenly deteriorated and died.

\section{DISCUSSION}

In the present case report, it was aimed to emphasize the challenges associated with the complexity, outcome and therapeutic options of PAVFs, along with literature review of neonatal cases. No more than 200 cases of PAVFs have been reported in the literature. Because of the rarity and that most authors have reported their own experiences, the exact incidence of PAVFs is not known (1). Depending on the angio-architecture of PAVFs, which varied among different ages, the presentation, treatment and outcome may be variable. A literature review of neonatal PAVF from 2005 to 2020 are summarized on Table (2-14).

It has been thought that most pediatric PAVFs develop antenatally, but prenatal diagnosis is rare. The cases detected antenatally are more prone to be symptomatic, either during the antenatal period or just after birth $(2,3,5)$. Abnormal angiogenesis seems to be the underlying pathophysiology in the formation of PAVF. It has been postulated that during early stage of vascular development, fistulous connection of the dilated capillary networks randomly persisted, and progression to the structured and more mature capillary network is disrupted $(1,4,15)$. This theory is supported by the evidence of molecular signaling pathways defects in some vascular syndromes including Klippel-Trenaunay-Weber syndrome, capillary malformation-AVM and hereditary hemorrhagic telangiectasia, which are frequently associated with PAVFs $(4,15)$. However, clinical features may not be apparent in infants, because the degree of the phenotypic expression in these syndromes increases with age $(2,4,15)$.

The PAVFs occur anywhere in the brain but frequently above the tentorium, showing multiplicity, particular in children (2,3). PAVF consists of a single or multiple arterial feeders in direct connection to a single venous drainage without an intervening tangle of vessels (1-4). The high pressure blood flow from arterial feeder directly into the venous drainage may result in venous varix formation, which detected more frequently in pediatric patients (1). The absence of capillary blood flow causes PAVFs to have a limited functional role in vascular feeding of the cerebral parenchyma. Therefore, these lesions may affect normal brain development, called as melting brain syndrome, and cause cognitive impairment due to low perfusion in the normal brain tissue and intracranial venous congestion $(2,4)$. Although it usually occurs bilaterally and symmetrically, brain atrophy around the lesion, as seen in the present case, can be present as a focal expression of the same phenomenon. The PAVFs with multiple arterial feeders are observed more often in infants, having high-flow arteriovenous shunting that is more likely to lead to congestive heart failure (1-4). They may also be presented with focal neurological symptoms such as a seizure or a hemorrhage $(2,3)$. In older children, hydrocephalus, developmental delay, focal neurologic deficits, headaches, seizures, and cerebral hemorrhage become common manifestations $(1,3,4)$.

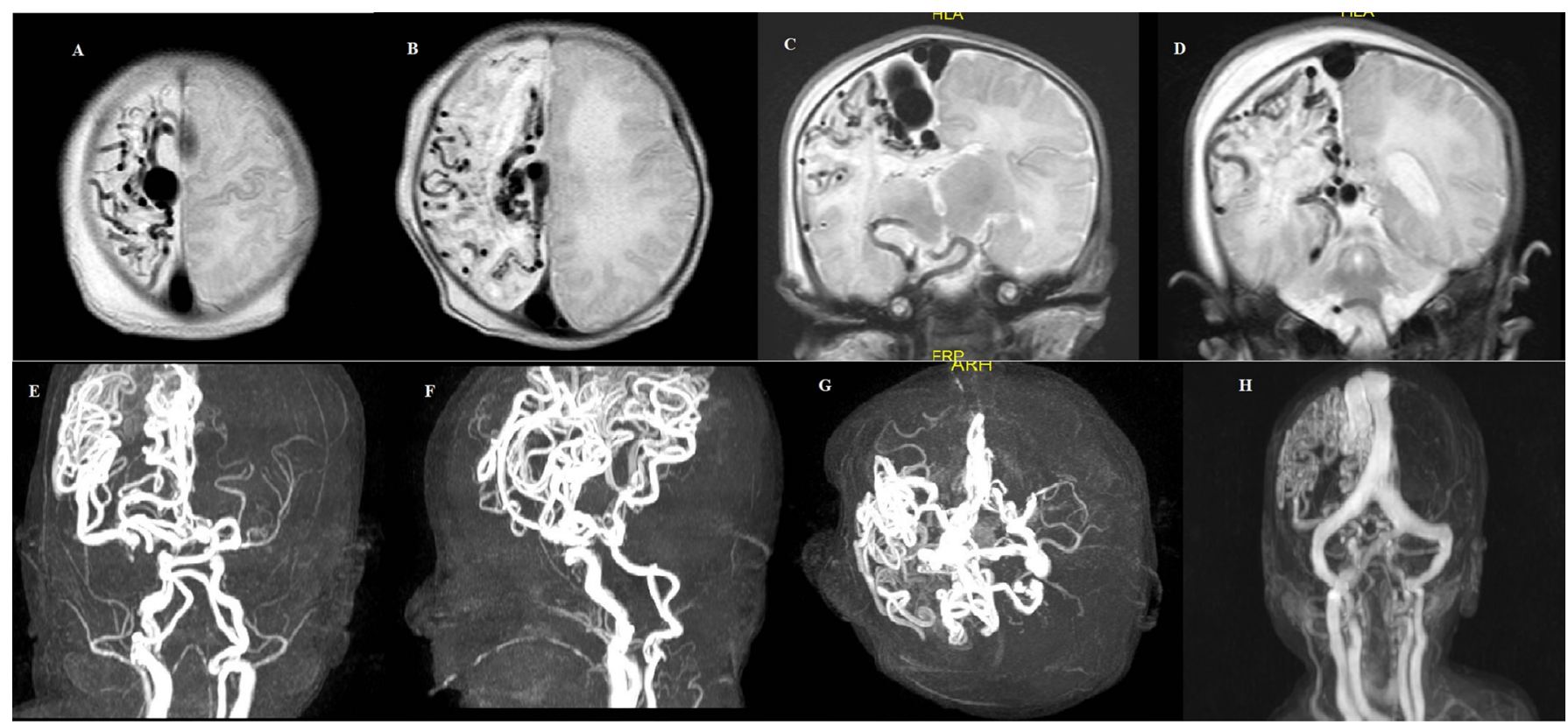

Figure. Axial (A,B) and coronal (C,D) T2-weighted magnetic resonance images show multiple tortuous signal void lesions on the right cerebral hemisphere, venous pouch and change of the signal intensity of gray matter and atrophy around the lesion. Cranial magnetic resonance angiography demonstrates a complex structure of multiple fistulas supplied by the branches of the right middle and posterior cerebral arteries communicating directly to an enlarged venous pouch beside the superior sagittal sinus (E-H). 


\begin{tabular}{|c|c|c|c|c|c|}
\hline Author, Year & $\begin{array}{l}\text { No of } \\
\text { case }\end{array}$ & $\begin{array}{l}\text { Prenatal } \\
\text { diagnosis }\end{array}$ & Clinical presentation & Treatment & Outcome $\dagger$ \\
\hline Garel, 2005 & 3 & Yes $(2 / 3)$ & $\begin{array}{l}\text { Cardiac failure }(2 / 3) \\
\text { Asymptomatic }(1 / 3)\end{array}$ & Endo $(3 / 3)$ & $\begin{array}{l}\text { Death }(1 / 3) \\
\text { Left hemiparesis }(1 / 3) \\
\text { Normal }(1 / 3)\end{array}$ \\
\hline Weon, 2005 & 21 & Yes $(4 / 21) \ddagger$ & $\begin{array}{l}\text { Cardiac failure }(15 / 21) \\
\text { Seizures }(3 / 21) \\
\text { Macrocrania }(2 / 21) \\
\text { Asymptomatic }(1 / 21)\end{array}$ & $\begin{array}{l}\text { Endo }(17 / 21) \\
\text { Untreated }(4 / 21) \& \\
\text { Radiotherapy }(1 / 21)\end{array}$ & $\begin{array}{l}\text { Death }(4 / 21) \\
\text { Normal(14/21) } \\
\text { Moderate or severe NS (3/21) }\end{array}$ \\
\hline Köroglu, 2006 & 1 & Yes & Cardiac failure & Endo & Neurologically delayed \\
\hline Lizuka, 2011 & 1 & No & Tachypnea & Endo & Normal \\
\hline Mascarenhas, 2012 & 1 & No & Cardiac failure & Endo & $\begin{array}{l}\text { Moderate psychomotor delay, } \\
\text { left hemiparesis }\end{array}$ \\
\hline Paramasivam, 2012 & 6 & Yes $(2 / 6)$ & $\begin{array}{l}\text { Cardiac failure }(4 / 6) \\
\text { Intracerebral hemorrhage (1/6) } \\
\text { Asymptomatic }(1 / 6)\end{array}$ & Endo & $\begin{array}{l}\text { Normal }(5 / 6) \\
\text { Death }(1 / 6)\end{array}$ \\
\hline Hetts, 2012 & 8 & Yes $(2 / 8)$ & $\begin{array}{l}\text { Cardiac failure }(7 / 8) \\
\text { Hydrocephalus }(1 / 8)\end{array}$ & $\begin{array}{l}\text { Endo }(5 / 8) \\
\text { Endo + surgery }(3 / 8)\end{array}$ & $\begin{array}{l}\text { Normal }(2 / 8) \\
\text { Death }(2 / 8) \\
\text { Severe or moderate NS }(4 / 8)\end{array}$ \\
\hline Kim, 2015 & 2 & No & Intracranial hemorrhage $(2 / 2)$ & Endo & $\begin{array}{l}\text { Developmental delay }(2 / 2) \\
\text { Left hemiparesis }(1 / 2)\end{array}$ \\
\hline Komiyama, 2016 & 3 & Not specified & Cardiac failure $(3 / 3)$ & Endo & $\begin{array}{l}\text { Normal }(1 / 3) \\
\text { Vegetative state }(1 / 3) \mathfrak{E} \\
\text { Death }(1 / 3) \mathfrak{E}\end{array}$ \\
\hline Ago, 2017 & 1 & No & Tachypnea & Surgery & Good \\
\hline Pedicelli, 2017 & 1 & Yes & Asymptomatic & Endo + Surgery & Mild development delay \\
\hline Maejima, 2018 & 1 & Yes & Cardiac failure & Endo & Death $£$ \\
\hline Terada, 2018 & 12 & Not specified & $\begin{array}{l}\text { Hidrovenous disorder }(8 / 12) \\
\text { Hemorrhage }(7 / 12) \text { Cardiac } \\
\text { failure }(6 / 12) \\
\text { Seizures }(3 / 12)\end{array}$ & $\begin{array}{l}\text { Endo }(10 / 12) \\
\text { Surgery }(4 / 12) \\
\text { Conservative }(1 / 12)\end{array}$ & $\begin{array}{l}\text { Favorable }(5 / 12) \\
\text { Unfavorable }(7 / 12)\end{array}$ \\
\hline \multicolumn{6}{|c|}{$\begin{array}{l}\text { † The definition of outcome may differ as per authors. } \\
\text { ₹ Two of them were diagnosed as vein of Galen aneurysmal malformation in utero. At birth three of them had heart failure; one was asymptomatic. } \\
8 \text { In } 3 \text { neonates, embolization was believed to be contra-indicated because of already existing brain damage. Two of them died, and the other one had severe disability. The last one } \\
\text { of untreated cases was lost at follow-up. } \\
\text { E Despite existing brain damage at birth, they had been treated at the request of parents. } \\
\text { Endo, endovascular embolization; NS, neurological symptoms/signs }\end{array}$} \\
\hline
\end{tabular}

In the suspected cases, MRI is the preferred imaging to demonstrate the anatomical location, possible feeders, presence of venous varix, and to show evidence of regional or diffuse cerebral injury (4). Digital subtraction angiogram is the gold standard for the diagnosis, and useful in identifying the angio-architecture of the fistula and in treatment planning $(1,4)$. Unfortunately, in the case presented here, digital subtraction angiogram could not be performed, so the anatomic and hemodynamic characteristics of the lesion were not detailed.

Indication and treatment strategy should be decided based on assessment of neurological, cardiac and other systemic manifestations and imaging studies of the lesion and the brain parenchyma. Because of the high risk of mortality and poor neurocognitive prognosis and that spontaneous obliteration of the fistula is extremely rare, curative treatment is the occlusion of the arteriovenous shunt by surgical, endovascular route or a combination of these modalities (1). Despite the presence of various factors influencing the choice of treatment strategies, endovascular approach is more preferable due to the less invasive nature of the procedure, the improvements in modern endovascular techniques and technologies, and increased endovascular experience (2-4,9). N-butyl2-cyanoacrylate-assisted (NBCA) and Onyx (ethylene vinyl alcohol copolymer) are the most commonly used materials during endovascular embolization (1-4). Each material has advantages and disadvantages (1). Endovascular treatment may be more challenging in featured conditions such as the presence of multiple feeders draining into the fistula or high flow feeder, and in small infants having heart failure and fragilities of the cerebrovascular system including difficulty of catheter access $(2,6)$. The presence of these conditions may necessitate a modification of the technique or perhaps a complementary surgical intervention for successful obliteration $(2,4)$. Surgical treatment is only reserved for a few cases in whom embolization is inconclusive, complicated with intraoperative intracranial hemorrhage or assumed too dangerous $(2,4)$. Small total blood volumes and coexistence of congestive heart failure make the surgery more risky in neonates (2).

The fact that complex fistulas with multiple arteriovenous connections are more common in small infants makes these lesion more likely to require several embolization sessions (2). Because only a limited the volume of contrast 
medium can be used in infants, it has been suggested that the aim here is to temporize congestive heart failure until after the first several months of life at which definitive treatment is more manageable (2). Furthermore, in case of a neonate who diagnosed with a PAFV prenatally or postnatally, even if being asymptomatic, an intervention can be considered to reduce shunting through the fistula because of its adverse effects on a developing brain $(2,3,6)$.

Clinical outcome seems to mainly depend on the complexity of the lesion and the age at diagnosis. The patients under 2 years of age have higher rates of mortality and procedural complications as well as poor neurologic and developmental outcomes (2). On followup after treatment, the patient should be monitored with MRI and if it is necessary, with cerebral angiogram, since recanalization, reactive angiogenesis with shunt, hydrocephalus and dural AVF may develop $(2,4)$. The natural history of brain damage, especially in prenatal cases, is extremely poor because they are irreversible, despite curative treatment. Therefore, existing brain damage is considered a contraindication to aggressive treatment $(3,6,8)$. As seen in the present case, when existing the findings of melting brain syndrome on the imagine studies, the parents should be carefully consulted regarding either high-risk procedures or poor prognosis. Nonetheless, therapeutic abstention might not be always possible if the parents requested to treat their child, despite eventually an unfavorable outcome $(6,8)$.

\section{CONCLUSION}

PAVFs are extremely rare vascular lesions, however, the rate of neonatal cases among all published ones seems remarkable. Neonatal PAVFs are likely to be more complicated, and usually presented with cardiac failure and more severe cerebral complications. Therefore, the treatment, either endovascular or surgical, is more challenging and associated with higher morbidity and mortality in neonates. Comprehensive prognostic evaluation and an optimal treatment strategy should be provided by a multidisciplinary team at specialized centers.

\section{ETHICAL DECLARATIONS}

Informed Consent: Written informed consent was obtained from all participants who participated in this study.

Referee Evaluation Process: Externally peer-reviewed.

Conflict of Interest Statement: The authors have no conflicts of interest to declare.

Financial Disclosure: The authors declared that this study has received no financial support.
Author Contributions: All of the authors declare that they have all participated in the design, execution, and analysis of the paper, and that they have approved the final version.

\section{REFERENCES}

1. Yu J, Shi L, Lv X, Wu Z, Yang H. Intracranial non-galenic pial arteriovenous fistula: A review of the literature. Interv Neuroradiol 2016; 22: 557-68.

2. Hetts S, Keenan K, Fullerton $\mathrm{H}$, et al. Pediatric intracranial nongalenic pial arteriovenous fistulas: clinical features, angioarchitecture and outcomes. Am J Neuroradiol 2012; 33: 1710-9.

3. Weon YC, Yoshida Y, Sachet M, et al. Supratentorial cerebral arteriovenous fistulas (AVFs) in children: review of 41 cases with 63 nonchoroidal single hole AVFs. Acta Neurochir 2005; 147: 17 31.

4. Paramasivam S, Toma N, Niimi Y, Berenstein A. Development, clinical presentation and endovascular management of congenital intracranial pial arteriovenous fistulas. Neuro Intervent Surg 2013; 5: 184-90.

5. Garel C, Azarian M, Lasjaunias P, et al. Pial arteriovenous fistulas: dilemmas in prenatal diagnosis, counseling and postnatal treatment. Report of three cases. Ultrasound Obstet Gynecol 2005; 26: $293 \mathrm{e} 6$

6. Komiyama M, Terada A, Ishiguro T. Neuro-Interventions for the Neonates with Brain Arteriovenous Fistulas: With Special Reference to Access Routes. Neurol Med Chir (Tokyo) 2016; 56: 132-40.

7. Maejima R, Ohshima T, Miyachi S, Matsuo N, Kawaguchi R, Takayasu M. Neonatal Intracranial Pial Arteriovenous Fistula Treated with Endovascular Embolization: A Case Report. World Neurosurg 2018; 118: 261-4.

8. Pedicelli A, Iacobucci M, Frassanito P, et al. Prenatal Diagnosis and Multimodal Neonatal Treatment of a Rare Pial Arteriovenous Fistula: Case Report and Review of the Literature. World Neurosurg 2017; 104: 1050.e13-1050.e18.

9. Terada A, Komiyama M, Ishiguro T, Niimi Y, Oishi H. Nationwide survey of pediatric intracranial arteriovenous shunts in Japan: Japanese Pediatric Arteriovenous Shunts Study (JPAS). J Neurosurg Pediatr 2018; 22: 550-8.

10. Iizuka Y, Murata N, Kohda E, et al. High-flow Neonatal Macrocerebral Arteriovenous Fistulas in Hereditary Hemorrhagic Telangiectasia. Neuroradiol J 2011; 24: 772-8.

11.Köroğlu M, Cil B, Yeşildağ A, Baykal B, Cekirge S, Oyar O. Prenatal diagnosis of intracranial pial arteriovenous fistula and endovascular treatment during the neonatal period. Diagn Interv Radiol 2006; 12: 64-7.

12. Kim SY, Eun HS, Shin JE, et al. Intracranial pial arteriovenous fistula presenting as brain hemorrhage in newborn infants. Neonatal Med 2015; 22: 228-32.

13. Mascarenhas MI, Moniz M, Ferreira S, Goulão A, Barroso R. High-output heart failure in a newborn. BMJ Case Rep 2012; 2012: bcr2012006289.

14. Ago M, Masumoto K, Uchiyama A, Aihara Y, Okada Y, Kusuda S. Serial Measurement of Superior Vena Cava Flow in Evaluation of the Clinical Severity of Pial Arteriovenous Fistula in an Infant. AJP Rep 2017; 7: e1-e4.

15. Walcott BP, Smith ER, Scott RM, Orbach DB. Pial arteriovenous fistulae in pediatric patients: associated syndromes and treatment outcome. J Neurointerv Surg 2013; 5: 10-4. 